\title{
The morphology and reproductive structures of Mediterranean species of the genus Nemastoma J. Agardh, nom. cons. (Nemastomataceae, Nemastomatales): Nemastoma dichotomum and $\mathbf{N}$. dumontioides
}

\author{
Conxi Rodríguez-Prieto ${ }^{1, *}$, Alba Vergés ${ }^{1}$, Noemí \\ Sánchez ${ }^{1}$, Lluís Polo ${ }^{1}$ and Marc Verlaque ${ }^{2}$ \\ 1 Universitat de Girona, Facultat de Ciencies, Campus \\ de Montilivi, 17071 Girona, Spain, e-mail: \\ conxi.rodriguez@udg.es \\ 2 UMR 6540 DIMAR, COM, Case 901, Parc Scientifique \\ et Technologique de Luminy, 13288 Marseille Cedex 09, \\ France \\ ${ }^{*}$ Corresponding author
}

\begin{abstract}
We investigated a collection of Nemastoma J. Agardh, nom. cons. (Nemastomatales, Rhodophyta), including the Mediterranean type material of species described by J. Agardh, Kützing and Ercegovic, and recent specimens from the Mediterranean Sea, Adriatic Sea and northeastern Atlantic Ocean. Based on their habit and vegetative and reproductive structures, we confirm that: (i) all the Mediterranean specimens studied belong to the genus Nemastoma; (ii) two species of Nemastoma co-exist in the Mediterranean Sea: (a) N. dichotomum, which is characterized by great plasticity of habit, a cartilaginous thallus in its basal and middle parts, and presumed reproduction exclusively by apomixis; and (b) N. dumontioides, which is characterized by a regularly pseudodichotomous, saccate-membranous thallus, and which reproduces both sexually and probably apomictically; and (iii) the Atlantic specimens attributed to N. dichotomum belong to other genera, and so, $N$. dichotomum is probably endemic to the Mediterranean Sea. Thus, three species described by Kützing have been reduced to varieties of Nemastoma dichotomum: (a) var. biasolettianum (Kützing) Rodríguez-Prieto, Verlaque et Vergés comb. nov. et stat. nov., with ligulate upper parts, (b) var. caulescens (Kützing) Rodríguez-Prieto, Verlaque et Vergés comb. nov. et stat. nov., with wedge-shaped upper parts, and (c) var. incrassatum (Kützing) Rodríguez-Prieto, Verlaque et Vergés comb. nov. et stat. nov., with spathulate upper parts. Finally, Nemastoma constrictum and N. constrictum var. longitrichogynum are placed in synonymy with $N$. dichotomum var. caulescens.
\end{abstract}

Keywords: Mediterranean Sea; morphology; Nemastoma; Nemastomataceae; reproductive structures.

\section{Introduction}

The genus Nemastoma J. Agardh nom. cons. (Nemastomataceae, Nemastomatales) includes less than 10 spe- cies distributed in the tropical, subtropical and warm temperate waters of both hemispheres (G.T. Kraft pers. comm.). In the Mediterranean Sea, it is currently represented by $N$. dichotomum J. Agardh and three other species of uncertain taxonomic position, $N$. dumontioides $\mathrm{J}$. Agardh, N. constrictum Ercegovic and N. inconspicuum Reinsch (Furnari et al. 1999, Athanasiadis 2002, Guiry and Nic Dhonncha 2003).

Agardh (1842: 89-90; as N. dichotoma) first described Nemastoma dichotomum, the type species of the genus (Silva 1980), from Trieste (Italy, Adriatic Sea) and Nice (France, western Mediterranean Sea). Of the original material, only that from the Adriatic Sea remains in the Herbarium of the Botanical Museum, Lund, Sweden (LD). In the absence of a holotype indicated by Agardh, one specimen (LD 22089) was selected by P. Robins (27 November 1984) as a lectotype, the other specimens being labeled as syntypes (P. Robins, msc.) (see Athanasiadis 1988, 1996). Kützing (1843: 390, pl. 74, figs iv 1-2) described Gymnophlaea dichotoma Kützing from Trieste, a taxon later considered conspecific with $N$. dichotomum by Kützing himself (1849), Agardh (1851), Berthold (1884) and Kylin (1932), and distinguished some particular morphological variations of $N$. dichotomum at a species or sub-species level: G. incrassata Kützing (1843: 390), G. biasolettiana Kützing (1843: 390-391), G. dichotoma var. tenuis Kützing (1866: 21, pl. 58) and G. caulescens Kützing (1866: 22, pl. 61). He also described a further species as Ginnania irregularis Kützing (1845: 299), later reduced to synonymy with $N$. dichotomum by G.B. De Toni (1905: 1662). The generic name Ginnania, which was proposed by Montagne (1839-1841), is a taxonomic synonym of Scinaia Bivona-Bernardi. It was based on G. furcellata (Turner) Montagne (basionym: Ulva furcellata Turner 1801), a synonym of Scinaia furcellata (Turner) J. Agardh. Because of the wide morphological diversity of all these taxa, Athanasiadis (1988) considered that, until a critical comparative study of the types or new collections from the type localities had been carried out, the relationship of $N$. dichotomum to these taxa described by Kützing would remain uncertain.

Some years after Kützing made his observations, Agardh $(1851,1876)$ considered G. biasolettiana and G. incrassata as synonyms of $N$. dichotomum and described a new Mediterranean species of Nemastoma, N. dumontioides J. Agardh (1851: 164), on the basis of a single putatively sterile specimen collected at Marseille (France). He characterized it by its saccate-membranous, Halymenia-like thallus which closely adhered to paper, in contrast to $N$. dichotomum which possesses a partly cartilaginous and less adherent thallus. According to Athan- 
asiadis (1988), an examination of the holotype confirmed that the vegetative structure of the species is similar to $N$. dichotomum, although, in the absence of reproductive organs, its identity remains obscure. Nemastoma dumontioides is not mentioned in AlgaeBase (Guiry and Nic Dhonncha 2003).

In 1875, Reinsch described another species from the Adriatic Sea, Nemastoma inconspicuum Reinsch (1875: 55: pl. xli, figs 1A-D; as N. inconspicua). According to the original description, the species grew epiphytically on Hypnea musciformis (Wulfen in Jacquin) J.V. Lamouroux, was 2-3 $\mathrm{mm}$ high and produced zonately divided tetrasporangia. This species has never been found subsequently. G.B. De Toni (1905: 1668) placed it in taxa excludenda, and Athanasiadis (2002) considered it to be of uncertain taxonomic position, mentioning that the occurrence of zonately divided tetrasporangia is the only reference of such structures in the genus.

Ercegovic described Nemastoma constrictum Ercegovic (1949: 40-44, figs 19-20; as N. constricta) from the Kornati Islands (Croatia, Adriatic Sea), which differs from $N$. dichotomum mainly by the presence of intercalary constrictions, situated at 0.5 or $1.0 \mathrm{~cm}$ below the bifurcations of the thallus, and by the 2-celled carpogonial branches inserted subapically on cortical fascicles. In $N$. dichotomum, no constrictions are reported and the carpogonial branch is usually 3-celled and situated laterally on rhizoidal adventitious filaments (Berthold 1884, Athanasiadis 1988). Ercegovic also described a variety of $N$. constrictum from the Adriatic Sea, $N$. constrictum var. longitrichogynum Ercegovic (1949: 44-47, figs 21-22; as $N$. constricta var. longitrichogyna), which differs from $N$. constrictum mainly by the presence of longer trichogynes (up to $1000 \mu \mathrm{m}$ in length). This latter variety has not been found again since its description, whereas $N$. constrictum is recorded from a later Adriatic collection by Ercegovic (1963).

Kylin (1956: 248) considered the absence of gland cells as a distinctive generic feature of the genus Nemastoma, although he acknowledged the occurrence of terminal gland cells in N. dumontioides (Kylin 1932). However, gland cells in Nemastoma dichotomum had been described and illustrated by Agardh (1879: 109, pl. iv, fig. 5) and their occurrence has been confirmed in all the confirmed species of Nemastoma (Reinsch 1875, Feldmann 1942, Ercegovic 1949, Ardré 1980, Athanasiadis 1988, Masuda and Guiry 1994, 1995).

Current knowledge of the life history and reproductive structures of the Mediterranean Nemastoma is limited. Kützing (1843: pl. 74, fig. iv-2) illustrated carposporophyte-like structures ('Kapselfrucht') in Gymnophlaea dichotoma Kützing, but the first detailed description and illustration of the female reproductive structures and development of the carposporophyte were made from Gulf of Naples specimens by Berthold (1884; as G. dichotoma Kützing). Berthold described carpogonial branches, auxiliary cells and the development of gonimoblasts on connecting filaments at a point close to the union of the connecting filament with the auxiliary cell (Berthold 1884, Oltmanns 1904, Kylin 1932). In the Adriatic Sea and in the Mediterranean Sea up to the present day, the only specimens (including the lectotype LD
22089) that have been reported as fertile, lack connecting filaments and have gonimoblasts that develop directly on the auxiliary cells (Athanasiadis 1988; as Nemastoma dichotomum) as a result of presumed apomixis. Male reproductive structures have never been described, although the syntypes LD 22088 and LD 22090 have been labeled as male gametophytes by Robins (msc. in Agardh Herbarium, LD). A filamentous stage reproducing by monospores has been observed in cultures of carpospores from plants of unknown origin (Cortel-Breeman and van den Hoek 1970, van den Hoek et al. 1972). Reinsch (1875: pl. xli, figs 2A, 2B; as Nemastoma dichotoma) described 'monospores' in $N$. dichotomum, but it appears on closer inspection of his figures that this author has confused gland cells with monosporangia.

The present paper aims at clarifying and describing in detail the morphology and the reproductive processes of the taxa of Nemastoma that occur in the Mediterranean Sea. We have studied an extensive collection of fresh and herbarium specimens from the Mediterranean Sea and elsewhere, including the type material of the species described by J. Agardh, Kützing and Ercegovic. This has allowed us to examine the vegetative and reproductive features of each species, enabling us to evaluate the range of variation and to select those characteristics that are most useful for species delineation.

\section{Materials and methods}

The following type materials and other collections were obtained on loan from LD and the Rijksherbarium, Leiden, The Netherlands (L):

- Ginnania irregularis Kützing: L 0487962, holotype, Trieste, Italy;

- Gymnophlaea biasolettiana Kützing: L 0487960, holotype, Trieste, Italy;

- G. caulescens Kützing: L 0487961, syntype, Pirano, Trieste, Italy;

- G. dichotoma var. tenuis Kützing: L 0487959, syntype, Trieste, Italy;

- G. incrassata Kützing: L 0487958, Trieste, Italy, October 1889, specimen collected by Kützing; the holotype is lacking in the Rijksherbarium, Leiden;

- Nemastoma dichotomum J. Agardh: LD 22089, lectotype, Trieste, Italy; syntypes: LD 22087, LD 22088, LD 22090, LD 22091, LD 22092, Trieste, Italy;

- Nemastoma dumontioides J. Agardh: LD 22078, holotype, Marseille, France.

Unfortunately, we failed to locate the holotypes of Gymnophlaea dichotoma Kützing and Nemastoma inconspicuum Reinsch. For the latter, the original drawing of the illustration published by Reinsch (1875) is the only document preserved in the Herbarium of the Naturhistorisches Museum, Vienna, Austria.

We also failed to locate the holotype of Nemastoma constrictum Ercegovic, although we did manage to obtain one specimen collected by Ercegovic in October 1938 at the type locality (Kornati Islands, Croatia, midAdriatic Sea) that is deposited in the J. Feldmann Herbarium, Muséum National d'Histoire Naturelle, France. 
Loans also included specimens deposited in the Herbaria of the Universities of Trieste, Italy (TSB-2639, Trieste, Italy; TSB-2646, Elaphonesos Island, Pariki, Greece; TSB-2642, Istria, Croatia) and Catania, Italy (CAT-870, Augusta, Italy), and the Centre d'Océanologie de Marseille, France ( $\mathrm{H}-3527$, Monaco; $\mathrm{H}-2354$, Corsica, France; $\mathrm{H}-2355$, Corsica, France). A photograph of the specimen studied by Berthold (1884) (no. 001502, Berthold Herbarium, Stazione Zoologica di Napoli, Italy) was kindly sent by Professor Maria Cristina Buia.

Atlantic specimens from the north of Spain referred to Nemastoma dichotomum and deposited in the Rijksherbarium, Leiden (L 0487967-L 0487969, Punta Abeleira, Pontevedra, Spain; L 0487968, Santa Clara, San Sebastián, Spain, leg. H. Stegenga, M.V. Wissen, I. Mol, A. Mulder and A.V. Beem) were also studied.

Specimens of Mediterranean Nemastoma were collected by SCUBA diving at different localities and preserved in $4 \%$ formalin/seawater or dried as herbarium specimens, supplemented by some specimens kindly given to the authors by $\operatorname{Dr} \mathrm{E}$. Ballesteros. Liquid-preserved specimens and exsiccata have been deposited in the Phycological Herbarium of the University of Girona, section algae (HGI-A 2512, Corsica, France, 26.viii.1992; HGI-A 4783, Corsica, France, 9.x.2001; HGI-A 5200, HGI-A 5295, and HGl-A 5296, Ibiza, Spain, 26.v.2001; HGI-A 5315, Pollença, Spain; HGI-A 5688, HGI-A 5689, HGI-A 5690, HGI-A 5691, HGI-A 5692 and HGI-A 5693, Columbretes Islands, Spain). A summary of the material examined is provided in Table 1.

Finally, we also examined the following specimens of Nemastoma canariense (Kützing) J. Agardh deposited in the Rijksherbarium, Leiden:

- L 0487955, leg. F.T. Kützing, Canary Islands;

- L 0487956, leg. F.T. Kützing, Canary Islands (?);

- L 0487963, Las Palmas, Canary Islands, 1.ii.1896, leg.

A. Vickers;

- L 0487964 and L 0487965, Graciosa Island, Canary Islands, 28.iii.1983, leg. W.F. Prud'homme van Reine;

- L 0487966, Montaña Clara Island, Canary Islands, 31.iii.1983, leg. W.F. Prud'homme van Reine.

Herbarium and liquid-preserved specimens were studied by hand-sectioning with a razor blade and by squash preparations previously treated with acidified aniline blue $(1-5 \%)$, a stain particularly effective for the examination of the reproductive structures of Nemastomataceae. Material was examined under a light microscope and features were drawn with a camera lucida. All morphological data are based on herbarium specimens. Habit photographs were taken with a Pentax Programa camera (objective Macro Sigma F28 of $50 \mathrm{~mm}$ ) and the light photomicrographs with a Nikon F-601M camera.

\section{Results}

The morphology and the vegetative and reproductive structures of the Mediterranean specimens show that all of them belong to the genus Nemastoma J. Agardh. All are gametophytic and possess: (i) a multiaxial structure and complete lack of secondary pit-connections; (ii) a lax filamentous medulla; (iii) a cortex of subdichotomous fascicles of cells that progressively decrease in size outwards; (iv) rhizoidal adventitious filaments produced by scattered inner cortical or medullary cells; and (v) terminal gland cells borne in the mid cortex. Fertile specimens have: (vi) a non-procarpic or a procarp-like (i.e., carpogonial branch and auxiliary cell borne on the same rhizoidal filament but carposporophytes develop on the auxiliary cell without any connection or fusion between auxiliary cell and neighboring carpogonia or other cells of the carpogonial branch) female structure; (vii) a simple 3-celled, occasionally 2- or 4-celled, carpogonial branch; (viii) rounded auxiliary cells intercalary in adventitious rhizoidal filaments and differentiating independently of fertilization; and (ix) connecting filaments (when present), multicellular, branched and able to effect successive diploidizations; ( $x$ ) gonimoblast development laterally and more or less outwardly directed (Table 2). Based on habit and vegetative and reproductive characters, it was confirmed that at least two species of Nemastoma co-exist in the Mediterranean Sea: $N$. dichotomum, which is characterized by a high morphological plasticity, basal and middle parts cartilaginous and the plants presumably reproducing exclusively by apomixis, and $N$. dumontioides, which is characterized by a uniformly pseudodichotomous, saccate-membranous thallus and both sexual and presumably apomictic reproduction.

In comparison with the collection of Nemastoma from the western Mediterranean Sea, the specimens from the Adriatic Sea have a high morphological diversity. Further investigations are required to determine the degree of genetic isolation between these variable Adriatic phenotypes, but the lack of significant differences in vegetative and reproductive structures and the fact that most of the specimens are from the same general locality (Trieste region, northern Adriatic Sea) have led us to attribute them all provisionally to $N$. dichotomum and to propose that the three most distinctive forms described as separated species by Kützing be reduced to varieties of Nemastoma dichotomum:

- N. dichotomum var. biasolettianum (Kützing) Rodríguez-Prieto, Verlaque et Vergés comb. nov. et stat. nov.;

- N. dichotomum var. caulescens (Kützing) RodríguezPrieto, Verlaque et Vergés comb. nov. et stat. nov.;

- N. dichotomum var. incrassatum (Kützing) RodríguezPrieto, Verlaque et Vergés comb. nov. et stat. nov.

The loss of the holotype means that the identity of Gymnophlaea dichotoma Kützing remains uncertain. The illustrations of its habit (Kützing 1843: pl. 74, fig. iv 1, Kützing 1866: 21 , pl. $58 \mathrm{~g}$ ) show an alga with a regular pseudodichotomous saccate thallus similar to those of $N$. dumontioides, which seems to indicate that the latter species also occurs in the Adriatic Sea (see also Ercegovic 1963: fig.17a) although it has not been collected there recently.

Also, the identity of the minute Nemastoma inconspicuum Reinsch cannot be resolved without a study of the holotype. The illustrations of its vegetative structure and 
Table 1 The collection of Nemastoma specimens studied, grouped by species and varieties.

\begin{tabular}{|c|c|c|c|c|c|}
\hline Specimen & Locality & Date & Labelled as & Leg. & $\begin{array}{l}\text { Type of } \\
\text { reproduction }\end{array}$ \\
\hline \multirow{2}{*}{$\begin{array}{l}\text { Nemastoma dichotomum } \\
\text { LD 22089, lectotype of } N . \\
\text { dichotomum, } q\end{array}$} & Trieste (IT) & - & Halymenia elongata? & J. Agardh & Apomixis \\
\hline & & & $\begin{array}{l}\text { Gymnophlaea incrassata? } \\
\text { Nemostoma dichotoma }\end{array}$ & & \\
\hline $\begin{array}{l}\text { LD 22087, syntype of } N \text {. } \\
\text { dichotomum, } q\end{array}$ & Trieste (IT) & - & Gymnophlaea furcellata? & J. Agardh & Apomixis \\
\hline $\begin{array}{l}\text { LD } 22090 \text {, syntype of } N . \\
\text { dichotomum, }+\delta^{*}\end{array}$ & Trieste (IT) & - & $\begin{array}{l}\text { Gymnophlaea dichotoma tab. } 58 \\
\text { Gymnophlaea furcellata? } \\
\text { Gymnophlaea dichotoma? }\end{array}$ & J. Agardh & Apomixis \\
\hline L 0487970, & Miramare, Trieste (IT) & ix.1875 & Nemastoma dichotoma & F. Hauck & Apomixis \\
\hline L 0487971, & Miramare, Trieste (IT) & - & Nemastoma dichotoma & F. Hauck & Apomixis \\
\hline $\begin{array}{l}\text { L 0487959, }+ \text {, syntype of } \\
\text { Gymnophlaea dichotoma var. } \\
\text { tenuis }\end{array}$ & Trieste (IT) & - & $\begin{array}{l}\text { Nemastoma dichotoma } \\
\text { Gymnophlaea dichotoma } \\
\text { var. tenuis }\end{array}$ & F. T. Kützing & Apomixis \\
\hline $\begin{array}{l}\text { L 0487962, holotype of } \\
\text { Ginnania irregularis }\end{array}$ & Trieste (IT) & - & $\begin{array}{l}\text { Ginnania irregularis } \\
\text { Gymnophlaea irregularis } \\
\text { Nemastoma dichotoma }\end{array}$ & F. T. Kützing & \\
\hline TSB 2634, & Miramare, Trieste (IT) & - & Nemastoma dichotoma & F. Hauck & Apomixis \\
\hline TSB 2635, 운 & Venice (IT) & vii.1960 & Nemastoma dichotoma & S. Pignatti & Apomixis \\
\hline TSB 2639, 운 & Duino, Trieste (IT) & 14.xii.1966 & Nemastoma dichotoma & G. Giaccone & Apomixis \\
\hline TSB 2643, ㅇ & St. Croce, Trieste (IT) & 13.vii.1966 & Nemastoma dichotoma & S. Pignatti & Apomixis \\
\hline \multicolumn{6}{|l|}{$\begin{array}{l}\text { N. dichotomum var. } \\
\text { biasolettianum }\end{array}$} \\
\hline $\begin{array}{l}\text { L 0487960, holotype of } \\
\text { G. biasolettiana, }+\end{array}$ & Trieste (IT) & - & $\begin{array}{l}\text { Gymnophlaea biasolettiana } \\
\text { Nemastoma dichotoma }\end{array}$ & F. T. Kützing & Apomixis \\
\hline $\begin{array}{l}\text { LD 22092, syntype of } \\
\text { N. dichotomum, }+\end{array}$ & Trieste (IT) & - & $\begin{array}{l}\text { Gymnophlaea biasolettiana } \\
\text { tab. } 59\end{array}$ & J. Agardh & Apomixis \\
\hline TSB 2646, o & Elaphonesos I., Pariki (GR) & 18.viii.1967 & Nemastoma dichotoma f. ligulata & G. Giaccone & Apomixis \\
\hline TSB 2651, 운 & Rovigno, Istria (HR) & $x .1891$ & Nemastoma dichotoma & Lucas & Apomixis \\
\hline \multicolumn{6}{|l|}{ N. dichotomum var. caulescens } \\
\hline $\begin{array}{l}\text { L 0487961, syntype of } \\
\text { G. caulescens, } \subsetneq\end{array}$ & Pirano (IT) & - & $\begin{array}{l}\text { Gymnophlaea caulescens } \\
\text { Nemastoma dichotoma }\end{array}$ & F. T. Kützing & Apomixis \\
\hline $\begin{array}{l}\text { LD 22088, syntype of } \\
\text { N. dichotomum, } \$ \$\end{array}$ & Trieste (IT) & - & $\begin{array}{l}\text { Gymnophlaea caulescens tab. } 61 \\
\text { Gymnophlaea dichotoma }\end{array}$ & J. Agardh & Apomixis \\
\hline 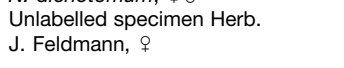 & Kornati Islands (HR) & x.1938 & Nemastoma constricta & A. Ercegovic & Apomixis \\
\hline \multicolumn{6}{|l|}{ N. dichotomum var. incrassatum } \\
\hline L 0487958 & Trieste (IT) & $\mathrm{x} .1889$ & $\begin{array}{l}\text { Gymnophlaea incrassata } \\
\text { Nemastoma dichotoma }\end{array}$ & F. T. Kützing & \\
\hline LD 22091, syntype of & Trieste (IT) & - & Gymnophlaea incrassate tab. 59 & J. Agardh & Apomixis \\
\hline TSB 2642 & Canale di Leme, Rovigno, Istria (HR) & 11.iii.1903 & Nemastoma dichotoma & N. Wille & \\
\hline \multicolumn{6}{|l|}{ Nemastoma dumontioides } \\
\hline LD 22078, holotype, $\delta$ & Marseilles (FR) & 1837 & Nemastoma dumontioides & J. Agardh & \\
\hline $\begin{array}{l}\text { no } 001502 \text {, } 9 \text {, Berthold } \\
\text { Herbarium, Stazione Zoologica } \\
\text { di Napoli, Italy }\end{array}$ & Naples (IT) & vi.1879 & Nemastoma dichotoma & G. Berthold & Sexual \\
\hline CAT- 870 , +9 & Augusta, Sicily (IT) & 28.vii.1975 & Nemastoma dichotomum & M. Cormaci & Sexual \\
\hline $\mathrm{H} 2354$, o & $\begin{array}{l}\text { Cavallu island, Lavezzi } \\
\text { Islands, Corsica (FR) }\end{array}$ & 21.x.1988 & Nemastoma dichotomum & M. Verlaque & Sexual \\
\hline H 2355 के & Corsica (FR) & 21.x.1988 & Nemastoma dichotomum & M. Verlaque & \\
\hline H 3527 , ㅇ & Larvotto, Monaco (FR) & 3.iv. 1997 & Nemastoma dichotomum & M. Verlaque & Apomixis \\
\hline HGI-A 2512, & Galéria, Corsica (FR) & 26.viii.1992 & Nemastoma dichotomum & C. Rodríguez-Prieto & Sexual \\
\hline HGI-A 4783 के & Corsica (FR) & 9.x.2001 & Nemastoma dichotomum & E. Ballesteros & \\
\hline HGI-A 5200 & Ibiza (ES) & 26.v.2001 & Nemastoma dichotomum & E. Ballesteros & \\
\hline HGI-A 5295 & Ibiza (ES) & 26.v.2001 & Nemastoma dichotomum & E. Ballesteros & \\
\hline HGI-A 5296, & Ibiza (ES) & 26.v.2001 & Nemastoma dichotomum & E. Ballesteros & Apomixis \\
\hline HGI-A 5315 & Pollenca (ES) & & Nemastoma dichotoma & E. Ballesteros & \\
\hline HGI-A 5688 & Columbretes I. (ES) & 10.v.2002 & Nemastoma dichotomum & C. Rodríguez-Prieto & \\
\hline HGI-A 5689 & Columbretes I. (ES) & 10.v.2002 & Nemastoma dichotomum & C. Rodríguez-Prieto & \\
\hline HGI-A 5690 & Columbretes I. (ES) & 10.v.2002 & Nemastoma dichotomum & C. Rodríguez-Prieto & \\
\hline HGI-A 5691 & Columbretes I. (ES) & 10.v.2002 & Nemastoma dichotomum & C. Rodríguez-Prieto & \\
\hline HGl-A 5692, ㅇ & Columbretes I. (ES) & 17.ix.2002 & Nemastoma dichotomum & $\begin{array}{l}\text { C. Rodríguez-Prieto and } \\
\text { N. Sánchez }\end{array}$ & Apomixis \\
\hline HGI-A 5693, & Columbretes I. (ES) & 17.ix.2002 & Nemastoma dichotomum & C. Rodríguez-Prieto and N. Sánchez & Apomixis \\
\hline
\end{tabular}

The number of the herbarium specimen, the locality, the date of collection, the name or names labelling the specimen, the collector (Leg.) and the type of reproduction are indicated.

zonate tetrasporangia (Reinsch 1875: 55: pl. xli, figs 1AD) suggest a possible tetrasporophyte of Nemastomataceae, but give no further relevant information.

Finally, Nemastoma constrictum Ercegovic and N. constrictum var. longitrichogynum Ercegovic do not differ in any significant way from each other or from $N$. dichotomum var. caulescens, and are here relegated to synonymy with the latter.

\section{Nemastoma dichotomum J. Agardh}

(Figures 1-23)

Protologue and illustrations: Agardh (1842), Algae maris Mediterranei et Adriatici, observationes in diagnosin specierum et dispositionem generum: 91 (as Nemastoma dichotoma); Agardh (1879: pl. iv, fig. 5).

Lectotype: LD 22089, + , Trieste, Italy, leg. J. Agardh (Figure 1).

Syntypes: LD 22087, $q$, LD 22088, $q$ đ , LD 22090, ㅇ o LD 22091, + o , LD 22092, + , Trieste, Italy, Adriatic Sea, leg. J. Agardh (Figures 2-6).

Heterotypic synonyms: Gymnophlaea dichotoma var. tenuis Kützing (1866: 21, pl. 58k); holotype: L 0487959, , Trieste, Italy, leg. F.T. Kützing (Figure 7). Ginnania irre- 
Table 2 A comparison between the taxonomic characteristics and the distribution of the types and authentic (i.e., collected by the author) specimens of Nemastoma.

\begin{tabular}{|c|c|c|c|c|c|c|c|c|c|c|c|c|c|c|}
\hline & & \multicolumn{5}{|c|}{ Nemastoma dichotomum } & \multicolumn{2}{|c|}{$\begin{array}{l}\text { N. dichotomum var. } \\
\text { biasolettianum }\end{array}$} & \multicolumn{3}{|c|}{ N. dichotomum var. caulescens } & \multicolumn{2}{|c|}{$\begin{array}{l}\text { N. dichotomum var. } \\
\text { incrassatum }\end{array}$} & \multirow{2}{*}{$\begin{array}{l}\text { Nemastoma dumontioides } \\
\text { LD } 22078\end{array}$} \\
\hline & & LD 22089 & LD 22087 & LD 22090 & L 0487959 & L 0487962 & L0487960 & LD 22092 & 0487961 & LD 22088 & Feldmann & L 0487958 & LD 22091 & \\
\hline $\begin{array}{l}\text { HABIT } \\
\text { Height (cm) } \\
\text { Thallus }\end{array}$ & $\begin{array}{l}\text { Base } \\
\text { Middle } \\
\text { Upper part }\end{array}$ & $\begin{array}{l}5 \\
\text { Cylindrical } \\
\text { Cylindrical- } \\
\text { compressed } \\
\text { Compressed }\end{array}$ & $\begin{array}{l}6-7 \\
\text { Cylindrical } \\
\text { Cylindrical- } \\
\text { compressed } \\
\text { Compressed }\end{array}$ & \multirow{3}{*}{$\begin{array}{l}5 \\
\text { Cylindrical } \\
\text { Cylindrical- } \\
\text { compressed } \\
\text { Cylindrical- } \\
\text { compressed } \\
\text { Cartilaginous } \\
\text { Cartilaginous- } \\
\text { membranous } \\
\text { Cartilaginous- } \\
\text { membranous } \\
? \\
1.5 \\
\text { Decreasing } \\
\text { Digitate }\end{array}$} & \multirow{3}{*}{$\begin{array}{l}2-3 \\
\text { Cylindrical } \\
\text { Cylindrical- } \\
\text { compressed } \\
\text { Cylindrical- } \\
\text { Compressed } \\
\text { Cartilaginous } \\
\text { Cartilaginous- } \\
\text { membranous } \\
\text { Cartilaginous- } \\
\text { membranous } \\
\text { No } \\
1 \\
\text { Decreasing } \\
\text { Digitate }\end{array}$} & \multirow{2}{*}{$\begin{array}{l}7-8 \\
\text { Clindrical } \\
\text { Cylindrical- } \\
\text { compressed } \\
\text { Cylindrical- } \\
\text { compressed } \\
\text { Cartilaginous } \\
\text { Membranous } \\
\text { Membranous }\end{array}$} & $\begin{array}{l}5-6 \\
\text { Cylindrical } \\
\text { Cylindrical- } \\
\text { compressed } \\
\text { Compressed }\end{array}$ & $\begin{array}{l}5 \\
\text { Cylindrical } \\
\text { Cylindrical- } \\
\text { compressed } \\
\text { Compressed }\end{array}$ & $\begin{array}{l}5 \\
\text { Cylindrical } \\
\text { Cylindrical } \\
\text { Compressed }\end{array}$ & $\begin{array}{l}\text { C-6 } \\
\text { Cyindrical } \\
\text { Cylindrical } \\
\text { Cylindrical- }\end{array}$ & $\begin{array}{l}7 \\
\text { Cylindrical } \\
\text { Cylindrical- } \\
\text { compressed } \\
\text { Compressed }\end{array}$ & $\begin{array}{l}\text { 3-4 } \\
\text { Cylindrical } \\
\text { Cylindrical } \\
\text { Compressed }\end{array}$ & $\begin{array}{l}\text { 5-6 } \\
\text { Cylindrical } \\
\text { Cylindrical }\end{array}$ & $\begin{array}{l}4-5 \\
\text { Cylindrical } \\
\text { Compressed } \\
\text { Compressed }\end{array}$ \\
\hline Texture & $\begin{array}{l}\text { Base } \\
\text { Middle } \\
\text { Upper part }\end{array}$ & $\begin{array}{l}\text { Cartilaginous } \\
\text { Cartilaginous- } \\
\text { membranous } \\
\text { Membranous }\end{array}$ & $\begin{array}{l}\text { Cartilaginous } \\
\text { Cartilaginous- } \\
\text { membranous } \\
\text { Membranous }\end{array}$ & & & & $\begin{array}{l}\text { Cartilaginous } \\
\text { Cartilaginous- } \\
\text { membranous } \\
\text { Membranous }\end{array}$ & $\begin{array}{l}\text { Cartilaginous } \\
\text { Cartilaginous- } \\
\text { membranous } \\
\text { Membranous }\end{array}$ & $\begin{array}{l}\text { Cartilaginous } \\
\text { Cartilaginous } \\
\text { Membranous }\end{array}$ & $\begin{array}{l}\text { Cartilaginous } \\
\text { Cartilaginous } \\
\text { Cartilaginous- } \\
\text { membranous }\end{array}$ & $\begin{array}{l}\text { Cartilaginous } \\
\text { Cartilaginous- } \\
\text { membranous } \\
\text { Membranous }\end{array}$ & $\begin{array}{l}\text { Cartilaginous } \\
\text { Cartilaginous } \\
\text { Membranous }\end{array}$ & $\begin{array}{l}\text { Cartilaginous } \\
\text { Cartilaginous } \\
\text { Membranous }\end{array}$ & $\begin{array}{l}\text { Cartilaginous } \\
\text { Membranous } \\
\text { Membranous }\end{array}$ \\
\hline $\begin{array}{l}\text { Base caespitose } \\
\text { Segments } \\
\text { Length of segments to the apex } \\
\text { Type of apex }\end{array}$ & Maximal width (mm) & $\begin{array}{l}? \\
2 \\
\text { Increasing } \\
\text { Ligulate }\end{array}$ & $\begin{array}{l}\text { No } \\
4-5 \\
\text { Decreasing } \\
\text { Wedge-shaped }\end{array}$ & & & $\begin{array}{l}\text { No } \\
1-2 \\
\text { Decreasing } \\
\text { Digitate }\end{array}$ & $\begin{array}{l}\text { No } \\
3 \\
\text { Increasing } \\
\text { Ligulate }\end{array}$ & $\begin{array}{l}\text { No } \\
3 \\
\text { Increasing } \\
\text { Ligulate }\end{array}$ & $\begin{array}{l}\text { Yes } \\
3 \\
\text { Decreasing } \\
\text { Wedge-shaped }\end{array}$ & $\begin{array}{l}? \\
1 \\
\text { Decreasing } \\
\text { Wedge-shaped }\end{array}$ & $\begin{array}{l}\text { No } \\
3 \\
\text { Decreasing } \\
\text { Wedge-shaped }\end{array}$ & $\begin{array}{l}\text { Yes } \\
1.5 \\
\text { Decreasing } \\
\text { Spathulate }\end{array}$ & $\begin{array}{l}\text { No } \\
1.5 \\
\text { Decreasing } \\
\text { Spathulate }\end{array}$ & $\begin{array}{l}? \\
5 \\
\text { Decreasing } \\
\text { Digitate }\end{array}$ \\
\hline \multicolumn{15}{|l|}{ VEGETATIVE STRUCTURES } \\
\hline $\begin{array}{l}\text { Outer cortical cells } \\
\text { Medullary cells } \\
\text { Rhizoidal cells } \\
\text { Gland cells } \\
\text { Presence of hyaline hairs }\end{array}$ & \multirow[t]{2}{*}{ 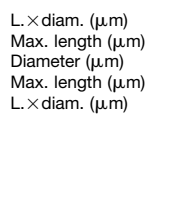 } & \multirow[t]{2}{*}{$\begin{array}{l}4-8 \times 4-6 \\
200 \\
6-8 \\
60 \\
10-24 \times 8-20 \\
\text { No }\end{array}$} & \multirow[t]{2}{*}{$\begin{array}{l}4-10 \times 4-6 \\
360 \\
6-10 \\
60 \\
10-22 \times 8-18 \\
\text { No }\end{array}$} & \multirow[t]{2}{*}{$\begin{array}{l}2-15 \times 6-8 \\
200 \\
8-12 \\
70 \\
18-36 \times 16-30 \\
\text { No }\end{array}$} & \multirow[t]{2}{*}{$\begin{array}{l}4-10 \times 6-8 \\
320 \\
6-10 \\
60 \\
18-22 \times 16-18 \\
\text { No }\end{array}$} & \multirow[t]{2}{*}{$\begin{array}{l}4-10 \times 6-8 \\
280 \\
6-10 \\
50 \\
20-26 \times 12-20 \\
\text { No }\end{array}$} & \multirow[t]{2}{*}{$\begin{array}{l}4-8 \times 6-8 \\
375 \\
6-10 \\
70 \\
17-25 \times 12-16 \\
\text { No }\end{array}$} & \multirow[t]{2}{*}{$\begin{array}{l}4-8 \times 8 \\
440 \\
8-12 \\
60 \\
18-24 \times 18 \\
\text { No }\end{array}$} & \multirow[t]{2}{*}{$\begin{array}{l}4-8 \times 6-8 \\
220 \\
6-10 \\
60 \\
24-28 \times 16-22 \\
\text { No }\end{array}$} & \multirow[t]{2}{*}{$\begin{array}{l}4-15 \times 4-6 \\
210 \\
6-10 \\
60 \\
16-26 \times 16-18 \\
\text { No }\end{array}$} & \multirow[t]{2}{*}{$\begin{array}{l}4-18 \times 2-6 \\
400 \\
4-8 \\
50 \\
10-24 \times 8-20 \\
\text { Yes }\end{array}$} & $\begin{array}{l}4 \times 6-8 \\
160 \\
6-10 \\
60 \\
10-18 \times 10-16 \\
\text { No }\end{array}$ & $\begin{array}{l}4-8 \times 6-8 \\
175 \\
5-10 \\
60 \\
12-26 \times 8-16 \\
\text { No }\end{array}$ & $\begin{array}{l}4-6 \times 2-6 \\
350 \\
6-10 \\
70 \\
12-23 \times 12-18 \\
\text { No }\end{array}$ \\
\hline REPRODUCTIVE STRUCTURES & & & & & & & & & & & & & & \\
\hline Carpogonial branch & & Yes & Yes & Yes & Yes & - & Yes & Yes & Yes & Yes & Yes & - & Yes & - \\
\hline & $\begin{array}{l}\text { No. of cells } \\
\text { Supporting cell } \\
\text { diam. }(\mu \mathrm{m})\end{array}$ & $\begin{array}{l}2-4 \\
10-15 \times 8-10\end{array}$ & $\begin{array}{l}3 \\
5-12\end{array}$ & $\begin{array}{l}(2-) 3 \\
10-13\end{array}$ & $\begin{array}{l}3 \\
?\end{array}$ & $\overline{-}$ & $\begin{array}{l}3 \\
10-12\end{array}$ & $\begin{array}{l}3 \\
10-12\end{array}$ & $\begin{array}{l}(2-)^{3} \\
10-12\end{array}$ & $\begin{array}{l}3 \\
10-12\end{array}$ & $\begin{array}{l}3 \\
12-14 \times 12\end{array}$ & - & $\begin{array}{l}3 \\
10-14\end{array}$ & $\overline{-}$ \\
\hline & $\begin{array}{l}\text { Hypogynous cell } \\
\text { diam }(\mu \mathrm{m})\end{array}$ & $8-10$ & $5-10$ & $6-8$ & $?$ & - & $6-8$ & $8-10$ & $6-8$ & $5-10$ & $8-10$ & - & $6-8$ & - \\
\hline & $\begin{array}{l}\text { Carpogonium } \\
\text { length }(\mu \mathrm{m})\end{array}$ & $5-40$ & $5-25$ & $10-40$ & $?$ & - & $5-10$ & $5-220$ & $5-10$ & $5-10$ & 20 & - & $5-25$ & - \\
\hline $\begin{array}{l}\text { Auxiliary cells } \\
\text { Connectina filaments }\end{array}$ & Diameter $(\mu \mathrm{m})$ & $7-13$ & 10-12 & $?$ & $10-12$ & - & $10-12$ & $8-10$ & 10-12 & 18 & $12-15$ & - & 10-12 & - \\
\hline $\begin{array}{l}\text { Connecting filar } \\
\text { Gonimoblast }\end{array}$ & $\begin{array}{l}\text { Presence } \\
\text { On auxiliary cell } \\
\text { Carposporangia }\end{array}$ & $\begin{array}{l}\text { Absent } \\
\text { Yes } \\
\text { Yes } \\
12-15\end{array}$ & $\begin{array}{l}\text { Absent } \\
\text { Yes } \\
\text { Yes } \\
\text { 10-24 }\end{array}$ & $\begin{array}{l}\text { Absent } \\
\text { Yes } \\
\text { Yes } \\
10-18\end{array}$ & $\begin{array}{l}\text { Absent } \\
\text { Yes } \\
\text { Yes } \\
10-24\end{array}$ & $\begin{array}{l}- \\
\overline{-}\end{array}$ & $\begin{array}{l}\text { Absent } \\
\text { Yes } \\
? \\
? \\
12-24\end{array}$ & $\begin{array}{l}\text { Absent } \\
\text { Yes } \\
\text { Yes } \\
17-22\end{array}$ & $\begin{array}{l}\text { Absent } \\
\text { Yes } \\
? \\
\text { 12-24 }\end{array}$ & $\begin{array}{l}\text { Absent } \\
\text { Yes } \\
\text { Yes } \\
12-20\end{array}$ & $\begin{array}{l}\text { Assent } \\
\text { Yes } \\
? \\
\text { 10-22 }\end{array}$ & $\begin{array}{l}- \\
\overline{-}\end{array}$ & $\begin{array}{l}\text { Absent } \\
\text { Yes } \\
\text { Yes } \\
10-22\end{array}$ & $\begin{array}{l}- \\
\overline{-}\end{array}$ \\
\hline Spermatangia & diam. (1) & Absent & Absent & Present & Absent & Absent & Absent & Absent & Absent & Present & Absent & Absent & Present & Present \\
\hline LOCALITY & & Trieste (l) & Trieste (I) & Trieste (I) & Trieste (l) & Trieste (I) & Trieste (l) & Trieste (I) & Trieste (l) & Trieste (l) & Kornati I. (CR) & Trieste (l) & Trieste (I) & Marseille $(F)$ \\
\hline
\end{tabular}



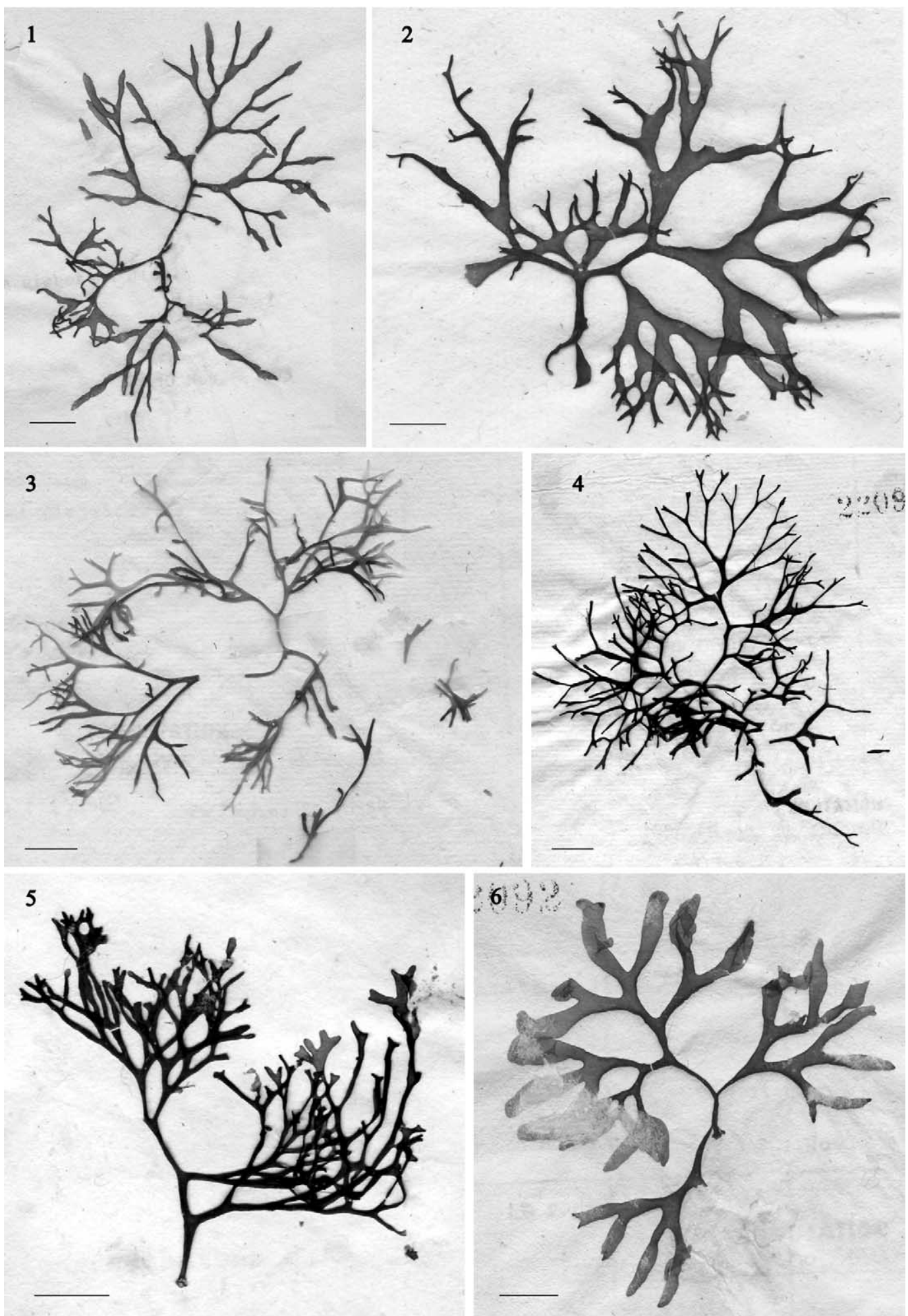

Figures 1-6 Nemastoma dichotomum J. Agardh, the type collection in the Herbarium J. Agardh (LD).

(1) Lectotype (LD 22089, \&), Trieste (IT). (2) Syntype (LD 22087, \&), Trieste (IT). (3) Syntype (LD 22088, $ᄋ$ o), Trieste (IT) (=N. dichotomum var. caulescens (Kützing) Rodríguez-Prieto, Verlaque et Vergés). (4) Syntype (LD 22090, 우), Trieste (IT). (5) Syntype (LD 22091, 우), Adriatic Sea (IT) (=N. dichotomum var. incrassatum (Kützing) Rodríguez-Prieto, Verlaque et Vergés). (6) Syntype (LD 22092, +), Trieste (IT) (=N. dichotomum var. biasolettianum (Kützing) Rodríguez-Prieto, Verlaque et Vergés). Scale bars for Figures $1-6=1 \mathrm{~cm}$.

gularis Kützing (1845: 299), Kützing (1866): 24, pl. 69ac); holotype: L 0487962, o, Trieste, Italy, leg. F.T. Kützing (Figure 8).

Specimens examined: see Table 1.
Habit: gametophytes to 7-8 $\mathrm{cm}$ high, arising from a discoid holdfast, occasionally caespitose; rosy, deeply red to red-brown or violet in colour; fronds cylindrical and cartilaginous basally, usually softer above; central parts cartilaginous, either cylindrical or compressed in dry specimens; plants irregularly pseudodichotomous, the 

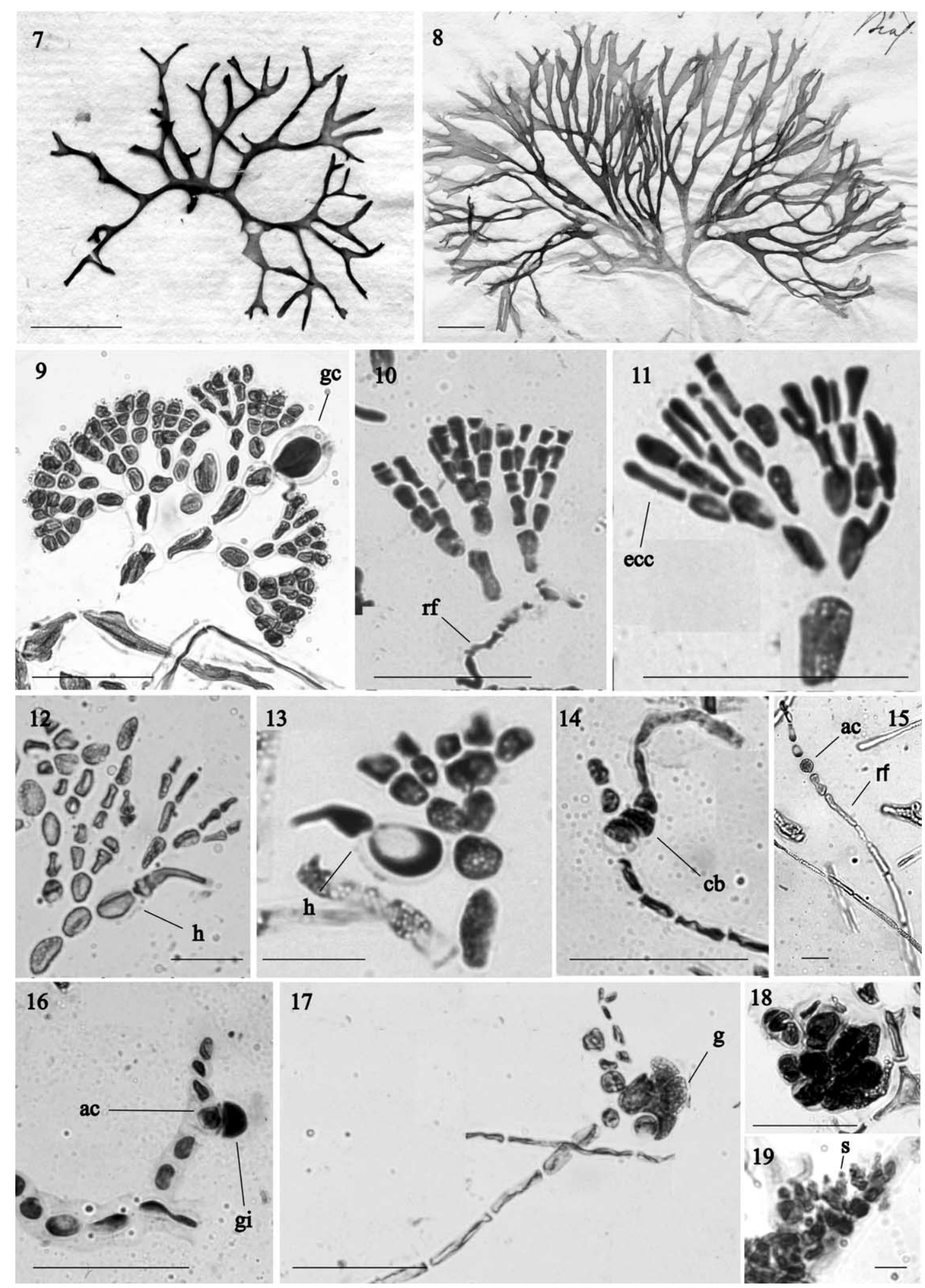

Figures 7-19 (7) Nemastoma dichotomum J. Agardh [Gymnophlaea dichotoma var. tenuis Kützing, holotype (L 0487959, +$)$, Trieste (IT)]. (8) Nemastoma dichotomum J. Agardh [Ginnania irregularis Kützing, holotype (L 0487962), Trieste (IT)]. (9-19) Vegetative and reproductive structures of Nemastoma dichotomum J. Agardh. (9) Cortical fascicle showing a gland cell (gc) (TSB 2639). (10) Cross section of cortex showing the beginning of a rhizoidal filament (rf), (Nemastoma constrictum Ercegovic, lectotype, PC). (11) Cross section of cortex showing some elongated outer cortical cells (ecc) (Nemastoma constrictum Ercegovic, lectotype, PC). (12-13). 'Glandular-like' hairs (h) (Nemastoma constrictum Ercegovic, lectotype, PC). (14) Three-celled carpogonial branch (cb) supported by a divided supporting cell and with a well-developed trichogyne (TSB 2639). (15) Auxiliary cell (ac) on a rhizoidal filament (rf) (Nemastoma constrictum Ercegovic, lectotype, PC). (16-17) Auxiliary cells (ac) giving rise to a gonimoblast initial (gi) (Figure 16) and young gonimoblast (g) (Figure 17) (TSB 2639). (18) Gonimoblasts in cross section, with carpospores developing in situ (TSB 2639). (19) Spermatangia (s) (LD 22088). Scale bars for Figures $7-8=1 \mathrm{~cm}$; for Figures $9-18=50 \mu \mathrm{m}$; for Figure $19=10 \mu \mathrm{m}$ ). 
branches, 1-5 mm broad, increasing slightly in breadth at the bifurcations, often fastigiate; lengths of the segments uniform except in upper parts; upper segments variable in length, digitate, ligulate, wedge-shaped or spathulate depending on the variety (see below); margins smooth, sometimes proliferous (Figures 1-8).

Vegetative structure: multiaxial, fronds composed of a broad, laxly-filamentous medulla of unpigmented elongated cells to $440 \mu \mathrm{m}$ long and $5-12 \mu \mathrm{m}$ in diameter, and a compact cortex subdichotomously divided to the sixth order, the outer cortical cells ovoid, club-shaped, slightly elongated or, occasionally very elongated, (4-) 8 $(-15) \mu \mathrm{m}$ long and (4-) 6-8 $\mu \mathrm{m}$ in diameter (Figures 9$11)$; secondary pit-connections absent; rhizoidal filaments adventitious, simple or subdichotomously branched, developed on the inner cortical cells or sometimes on the medullary filaments and transversing the thallus; cells of rhizoidal filaments shorter (up to $70 \mu \mathrm{m}$ in length) and with denser content than medullary cells; terminal gland cells present within the sub-surface layers of the cortex, subspherical to ovoid, 10-28 (-38) $\mu \mathrm{m}$ long and 8-22 (-30) $\mu \mathrm{m}$ in diameter; 'glandular-like' hairs occasionally present at the place of a cortical dichotomy (Figures 12-13).

Reproduction: plants monoecious; female reproductive structures non-procarpic or procarp-like (carpogonial branch and auxiliary cell borne on the same rhizoidal filament); female gametophytes monocarpogonical; carpogonial branches 3-celled (occasionally 2- or 4-celled), borne laterally on a modified intercalary vegetative cell of rhizoidal filaments, the supporting cell rounded or ovoid, (5-) 12-14 $\mu \mathrm{m}$ long and (5-) 8-12 $\mu \mathrm{m}$ in diameter, occasionally divided into two hemispherical cells; hypogynous cells 5-10 $\mu \mathrm{m}$ in diameter; trichogynes, simple or occasionally bifurcate, usually $5-40 \mu \mathrm{m}$ in length, occasionally up to $220 \mu \mathrm{m}$ (Figure 14); auxiliary cells intercalary on rhizoidal filaments, enlarged and dark-staining prior to presumed diploidization, 8-18 $\mu \mathrm{m}$ in diameter (Figure $15)$; occasionally, two auxiliary cells borne on the same rhizoidal filament; nutritive cells absent; connecting filaments not observed; gonimoblast initial arising from auxiliary cell, presumably by apomixis (Figures 16-17); gonimoblast development lateral or outward; carposporophytes scattered over the thallus, covered by a thin hyaline membrane and apparently formed by two gonimolobes; all gonimoblast cells becoming carposporangia, 10-24 $\mu \mathrm{m}$ in diameter, occasionally germinating in situ (Figure 18); male gametophytes apparently uncommon; spermatangia rounded, $1-3 \mu \mathrm{m}$ in diameter and cut off from the terminal cortical cells, single or in groups of 2-3 (Figure 19); tetrasporophytes unknown.

Distribution: Adriatic, Aegean and Ionian Seas. Atlantic specimens from the north of Spain and deposited as Nemastoma dichotomum in the Rijksherbarium, Leiden (L) are misidentifications and do not belong to the genus Nemastoma, as having a filamentous medulla with some stellate cells.

\section{N. dichotomum var. biasolettianum (Kützing) Rodríguez-Prieto, Verlaque et Vergés comb. nov. et stat. nov. \\ (Figures 6, 20)}

Basionym: Gymnophlaea biasolettiana Kützing (1843), Phycologia generalis (oder Anatomie, Physiologie und Systemkunde der Tange): 390-391.

Illustrations: Kützing (1866: 21, pl. 59d-e).

Holotype: L 0487960, \&, Trieste, Italy, leg. F.T. Kützing (Figure 20).

Specimens examined: see Table 1 . The specimen LD 22092, + (syntype of $N$. dichotomum labeled ' $G$. biasolettiana, Trieste, Italy') is probably from the same collection that included the holotype of G. biasolettiana (Figure $6)$.

Habit: gametophytes to $6 \mathrm{~cm}$ high, basal parts cylindrical, cartilaginous; median parts cylindrical or compressed; interdichotomies increasing in length distally, $<3 \mathrm{~mm}$ wide except at the bifurcations, where they can slightly increase in breadth; differs from var. dichotomum in its upper parts ligulate, compressed and membranous in dry specimens.

Distribution: Adriatic, Aegean and Ionian Seas.

\section{N. dichotomum var. caulescens (Kützing) Rodríguez- Prieto, Verlaque et Vergés comb. nov. et stat. nov.}

(Figures 3, 21-22)

Basionym: Gymnophlaea caulescens Kützing (1866), Tabulae phycologicae, oder Abbildungen der Tange: 22, pl. $61 \mathrm{a}-\mathrm{c}$.

Syntype: L 0487961 (two specimens), $\uparrow$, Pirano, Trieste, Italy, leg. F.T. Kützing (Figure 21).

Heterotypic synonyms: Nemastoma constrictum Ercegovic (1949: 40-44, figs 20-21; as $N$. constricta); type locality: Kornati Islands, middle Adriatic Sea; holotype presumed to have been destroyed; lectotype designated herein: unnumbered specimen collected by Ercegovic himself, in October 1938, at the type locality (one month after the collection of the holotype), $q$, labeled "Nemastoma constrictum, leg. Ercegovic, October 1838, Kornati Islands, Croatia" and deposited in the J. Feldmann Herbarium, Muséum National d'Histoire Naturelle (PC) (Figure 22). $N$. constrictum var. longitrichogynum Ercegovic (1949): 44-47, figs 22-23; as N. constricta var. longitrichogyna); type locality: middle Adriatic Sea; holotype presumed to have been destroyed.

Other specimens examined: see Table 1. The specimen LD 22088, + o (syntype of $N$. dichotomum labeled ' $G$. caulescens, Trieste, Italy') belongs to this variety (Figure 3).

Habit: gametophytes to $7 \mathrm{~cm}$ high, basal and medium parts cylindrical or slightly compressed, cartilaginous in texture; interdichotomies $<3 \mathrm{~mm}$ wide throughout 

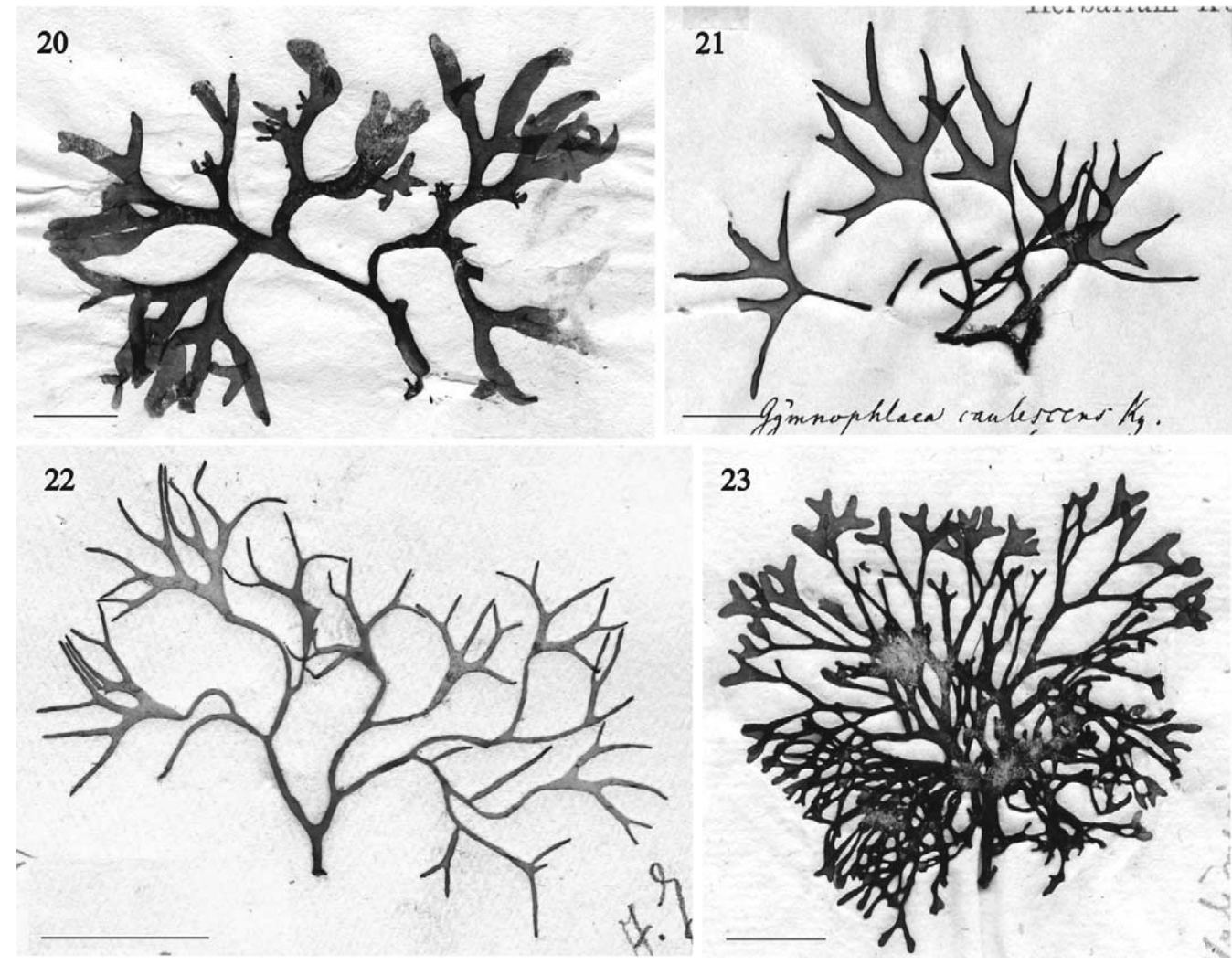

Figures 20-23 Nemastoma dichotomum.

(20) Nemastoma dichotomum var. biasolettianum (Kützing) Rodríguez-Prieto, Verlaque et Vergés [Gymnophlaea biasolettiana Kützing, holotype (L 0487960, \&), Trieste (IT)]. (21) Nemastoma dichotomum var. caulescens (Kützing) Rodríguez-Prieto, Verlaque et Vergés [Gymnophlaea caulescens Kützing, syntype (L 0487961, ९), Trieste (IT)]. (22) Nemastoma dichotomum var. caulescens [Nemastoma constrictum Ercegovic, lectotype, Kornati islands (CR); published by permission of the Muséum National d'Histoire Naturelle, Herbier Cryptogamique (PC)]. (23) Nemastoma dichotomum var. incrassatum (Kützing) Rodríguez-Prieto, Verlaque et Vergés [Gymnophlaea incrassata Kützing, lectotype ( $\mathrm{L}$ 0487958), Trieste (IT)]. Scale bars for Figures $20-23=1 \mathrm{~cm}$.

except for the bifurcations, which are up to $5 \mathrm{~mm}$ wide; differs from var. dichotomum in its upper parts wedgeshaped, compressed and membranous in dry specimens.

The lectotype of Nemastoma constrictum showed no differences from the syntype of Gymnophlaea caulescens Kützing (Table 2). As suggested by Athanasiadis (1988), the structures regarded by Ercegovic as being 2-celled carpogonial branches with long trichogynes are hairs ('glandular-like' hairs) (Figures 12-13). Nemastoma constrictum var. longitrichogynum Ercegovic probably corresponds to $N$. dichotomum var. caulescens, as it differs only by its exceptionally long 'glandular-like' hairs (up to $1000 \mu \mathrm{m}$ long).

Distribution: Adriatic Sea.

\section{N. dichotomum var. incrassatum (Kützing)}

Rodríguez-Prieto, Verlaque et Vergés comb. nov. et stat. nov.

(Figures 5, 23)

Basionym: Gymnophlaea incrassata Kützing (1843), Phycologia generalis (oder Anatomie, Physiologie und Systemkunde der Tange): 390.

Illustrations: Kützing (1866: 21, pl. 59).
Holotype: not located in the Rijksherbarium, Leiden; type locality: Adriatic Sea.

Lectotype designated herein: L 0487958, sterile, labeled "Gymnophlaea incrassata, leg. Kützing, x.1889, Trieste, Italy" (Figure 23).

Specimens examined: see Table 1 . The specimen LD 22091, 우 (syntype of $N$. dichotomum labeled $G$. incrassata, Adriatic Sea, belongs to this variety (Figure 5).

Habit: gametophytes to $6 \mathrm{~cm}$ high; basal and medium part of the thallus terete, filiform and cartilaginous; segments decreasing in length towards the upper parts and less than $1.5 \mathrm{~mm}$ wide except in the bifurcations where they can slightly increase in breadth $(1.5-2.0 \mathrm{~mm})$; differs from var. dichotomum in its upper parts spathulate and membranous in dry specimens.

\section{Distribution: Adriatic Sea.}

Nemastoma dumontioides J. Agardh (Figures 24-44)

Protologue: Agardh (1851), Species genera et ordines algarum, seu descriptiones succinctae specierum, generum et ordinum, quibus constituitur. Vol. 2: Florideae. Part 1: 164. 
Illustrations: Kylin (1932: pl. i, fig. 1, holotype); Berthold (1884: pl. iv, fig. 3, pl. vi, figs 9-15, as Gymnophlaea dichotoma Kützing); Oltmanns (1904: fig. 326-1, as Gymnophlaea dichotoma).

Holotype: LD 22078, o, Marseille, France, leg. J. Agardh (Figure 24). The holotype is a male gametophyte, although spermatangia are not described in the protologue.

Specimens examined: see Table 1. An examination of the photograph of the specimen studied by Berthold (1884): specimen 001502, labeled "Gymnophlaea dichotoma Kützing, Gulf of Naples”, Berthold Herbarium, courtesy of the Stazione Zoologica di Napoli, Italy (Figure 25), showed that the alga is $N$. dumontioides, although the author failed to describe or illustrate gland cells.

Habit: gametophytes to $8 \mathrm{~cm}$ high, arising from a discoid holdfast; fronds often caespitose, rosy, deeply red to redbrown in colour; thallus membranous throughout in dry specimens, cylindrical or compressed and gelatinous in fresh specimens (Figures 26-27), very regularly pseudodichotomously branched; branches often fastigiated and corymbiform in outline, 4-5 $\mathrm{mm}$ broad, increasing slightly in breadth at the bifurcations; length of the interdichotomies uniform proximally, shorter distally; terminal segments digitate or occasionally ligulate; axes smooth but sometimes proliferous (Figures 24-27).

Vegetative structure: similar to that of $N$. dichotomum; unpigmented elongated medullary cells, to $350 \mu \mathrm{m}$ long and $6(-10) \mu \mathrm{m}$ in diameter; cortex compact, subdichotomously divided to the sixth order (Figures 28-30); outer cortical cells ovoid, club-shaped or, occasionally, slightly elongated (2-) 6-8 $\times 4-6 \mu \mathrm{m}$ (Figure 29); rhizoidal filaments adventitious, to $70 \mu \mathrm{m}$ in length, transversing the thallus (Figure 30); terminal subsurface gland cells always present (Figure 30 ), subspherical, $12-23 \times 12-18 \mu \mathrm{m}$; vegetative 'glandular-like' hairs hyaline, up to $2000 \mu \mathrm{m}$ long, observed in only one specimen (H 3527, Monaco) (Figures 31-32).

Reproduction: plants dioecious; female gametophytes monocarpogonical and non-procarpic (Figures 33-36) or occasionally procarpic-like (carpogonial branch and auxiliary cell borne on the same rhizoidal filament) (Figures 37-38); carpogonial branches 3-celled (occasionally 2celled) borne laterally (terminally in one specimen: CAT 870 , Sicily) on a modified vegetative cell of a rhizoidal filament (Figures 33-34) or, very rarely, lateral on cortical fascicles (Figure 39); supporting cell rounded or ovoid, 10-14 long and 10-12 $\mu \mathrm{m}$ in diameter, usually divided into two hemispherical cells; hypogynous cells $8-10 \mu \mathrm{m}$ in diameter; trichogynes simple or occasionally bifurcate, to $240 \mu \mathrm{m}$ in length; auxiliary cells rounded, intercalary in rhizoidal filaments, enlarged and dark-staining prior to presumed diploidization, 14-17 $\mu \mathrm{m}$ in diameter (Figures 35-38); two auxiliary cells occasionally borne on the same rhizoidal filament (Figure 36); nutritive cells absent; presumably following fertilization, a connecting filament is initiated by the basal cell of the carpogonial branch and issue head on from it (Figure 40) growing parallel to the frond surface; connecting filaments septate, branched, 1-2 $\mu \mathrm{m}$ in diameter, connecting laterally with auxiliary cells and able to effect successive diploidizations (Figure 41); gonimoblast initial arising from the connecting filament adjacent to its point of fusion to the auxiliary cell (Figure 42); carposporophytes scattered over the thallus and covered by a thin hyaline membrane, all gonimoblast cells becoming carposporangia, 12$23 \mu \mathrm{m}$ in diameter; in some individuals, connecting filament absent and gonimoblast initial arising from auxiliary cell presumably by apomixis; gonimoblast development outward; male gametophytes apparently not very frequent (Table 1); spermatangia rounded, to 1-2 $\mu \mathrm{m}$ in diameter, cut off from the terminal cortical cells, singly or in groups of 2-3 (Figures 43-44); tetrasporophyte unknown.

Distribution: western Mediterranean Sea, Adriatic Sea (?).

\section{Discussion}

The red alga family Nemastomataceae, placed now in the resurrected order Nemastomatales Kylin emend. G.W. Saunders et Kraft (2002), currently includes the following four genera: Adelophycus Kraft in Womersley (1994), Itonoa Masuda and Guiry (1995), Nemastoma J. Agardh (1842) and Predaea G. De Toni (1936). The vegetative and reproductive structures of type materials and recent collections of Mediterranean specimens confirm that the diagnostic features of the genus Nemastoma J. Agardh (Masuda and Guiry 1994, 1995) are: (i) terminal subsurface gland cells; (ii) supporting cells and auxiliary cells intercalary on adventitious filaments; (iii) carpogonial branches lacking sterile laterals; (iv) no nutritive cells on hypogenous or supporting cells; (v) no nutritive auxiliary cells; and, (vi) connecting filaments (when present), multicellular, branched and able to effect successive diploidizations; (vii) gonimoblast initial arising from the connecting filament adjacent to its point of fusion with the auxiliary cell; (viii) gonimoblast development lateral or outward; and (ix) tetrasporophyte unknown.

According to Saunders and Kraft (2002), the Nemastomatales have 3-5-celled carpogonial branches, but 2-celled carpogonial branches have occasionally been observed in $N$. dumontioides and are the normal features of several Predaea species (Kraft 1984, Verlaque 1990).

Moreover, our findings indicate that the Nemastomataceae generally include non-procarpic genera, where the zygote is successively transferred to several auxiliary cells, and that connecting filaments in Nemastoma can be issued from the basal cell of the carpogonial branch (rather then the carpogonium itself). The latter feature appears to be the only one presently segregating Nemastoma from Adelophycus. On the other hand, the procarplike condition (occasionally seen in both apomictic and sexual plants of Nemastoma) can be fortuitous (connec- 

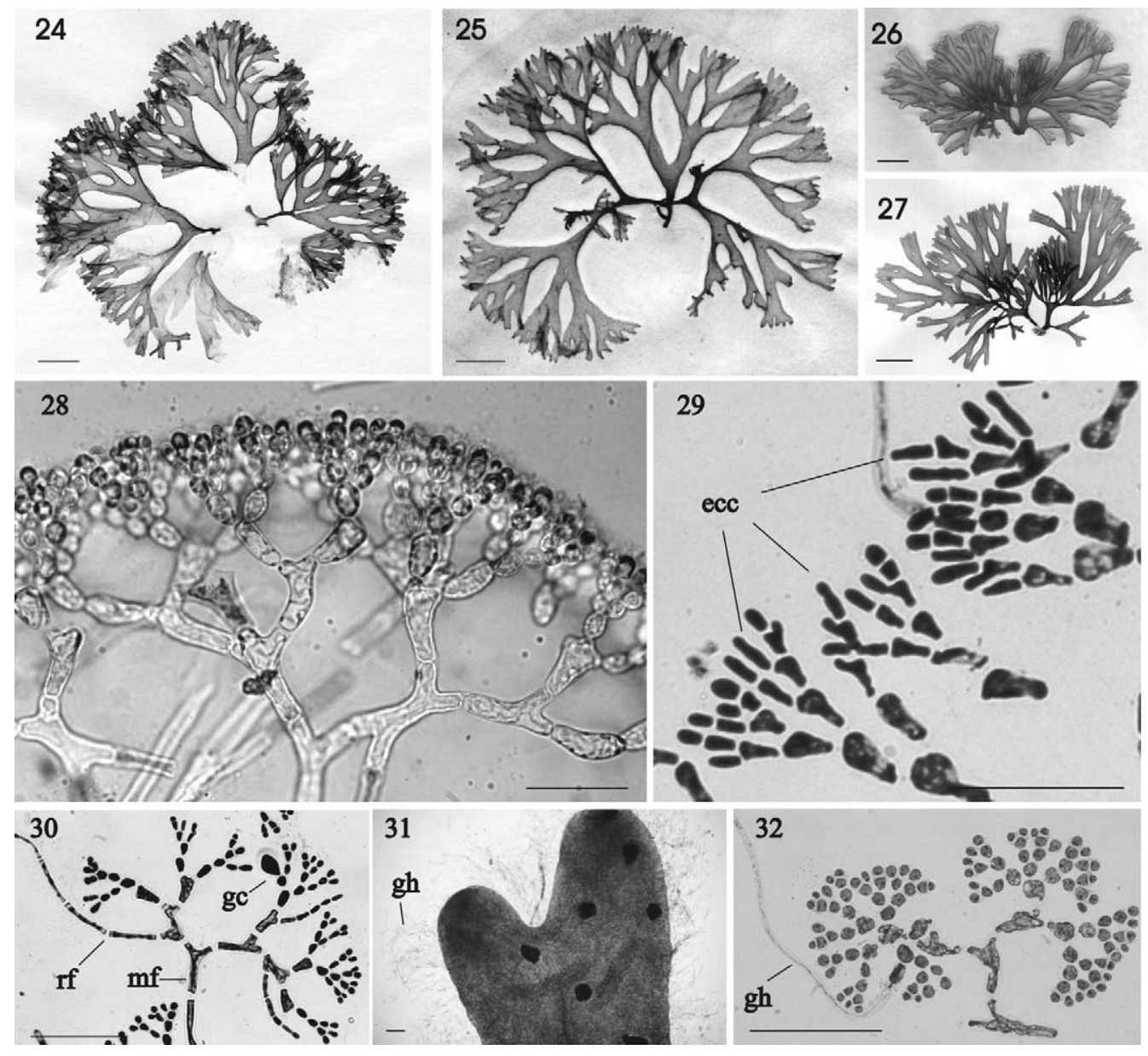

Figures 24-32 Nemastoma dumontioides J. Agardh.

(24) Holotype (LD 22078, §), Marseilles (FR). (25) Specimen of Gymnophlaea dichotoma Kützing described and illustrated by G. Berthold (1884) (Berthold Herbarium no. 001502, +), Gulf of Naples (IT). (26-27) Specimen HGI-A 5690 from the Columbretes Islands (ES) (legit C. Rodríguez-Prieto). Liquid-preserved (Figure 26) and pressed specimen (Figure 27). (28) Cross section of cortex of a slightly staining specimen (HGI-A 5692). (29) Cross section of a hardly staining and squashed specimen; cortex with elongated cortical cells (ecc) (H 3527). (30) Cross section showing a cortical fascicle with a medullary filament (mf), a rhizoidal filament (rf) and a gland cell (gc) (H 3527). (31) Branch tip of a specimen densely invested with 'glandular-like' hairs (gh) $(\mathrm{H}$ 3527). (32) Cross section of $\mathrm{H}$ 3527 showing a cortical fascicle with a 'glandular-like' hair (gh) (H 3527). Scale bars for Figures $24-27=1 \mathrm{~cm}$; for Figures $28-30$ and $32=100 \mu \mathrm{m}$; for Figure $31=200 \mu \mathrm{m}$.

tion or fusion between auxiliary cell and neighboring carpogonia or other cells of the carpogonial branch never observed), or represent a plesiomorphy (i.e., a relic condition), as generally evident in the procarpic and primitive Ceramiales (see fig. 2 in Athanasiadis 2002), or, as well, a new type, homologous to that reported in the sistertaxon Schizymeniaceae where the connecting filament first fuses with proximal nutritive auxiliary cells before departing to meet remote ones (Masuda and Guiry 1995: 66).

Two species of Nemastoma co-exist in the Mediterranean Sea: $N$. dichotomum J. Agardh, recorded widely but infrequently in the Adriatic, Aegean and Ionian Seas, and $N$. dumontioides J. Agardh, restricted to the western Mediterranean but possibly extending eastward into the Adriatic Sea. They differ mainly in habit, the reproductive structures and the presumably exclusively apomictic reproduction in $N$. dichotomum (Table 3 ). Athanasiadis (1988) reported that plants of $N$. dichotomum are composed of one to several terete to slightly compressed fronds, but our findings show that this is equally true of $N$. dumontioides and cannot be considered a good tax- onomic character. The two species may also differ in that Nemastoma dichotomum is presumed monoecious whereas $N$. dumontioides is regarded as dioecious in the present work, but this characteristic requires confirmation because male structures can be difficult to recognize, or may be protrandous.

Nemastoma dichotomum and $N$. dumontioides appear to be restricted to the Mediterranean Sea. Atlantic specimens from Spain of Nemastoma dichotomum conserved in $L$ are misidentifications, as is probably the case with other previous Atlantic records: Channel Islands (Lyle 1920), regarded as a misidentification by Dixon and Irvine (1977); Madeira (Levring 1974), refuted by Athanasiadis (1987); and the report of an undescribed species of Nemastoma from Ireland (Guiry, pers. comm. in Athanasiadis 1996: 68). A little known species of Nemastoma, N. canariense (Kützing) J. Agardh, occurs in the Canary Islands. Canarian specimens deposited in $\mathrm{L}$ showed that $N$. canariense differs from the Mediterranean taxa of Nemastoma in having a narrower cartilaginous thallus (1.5 mm broad), a thicker cortical layer and larger gland cells (see also Børgesen 1929). 

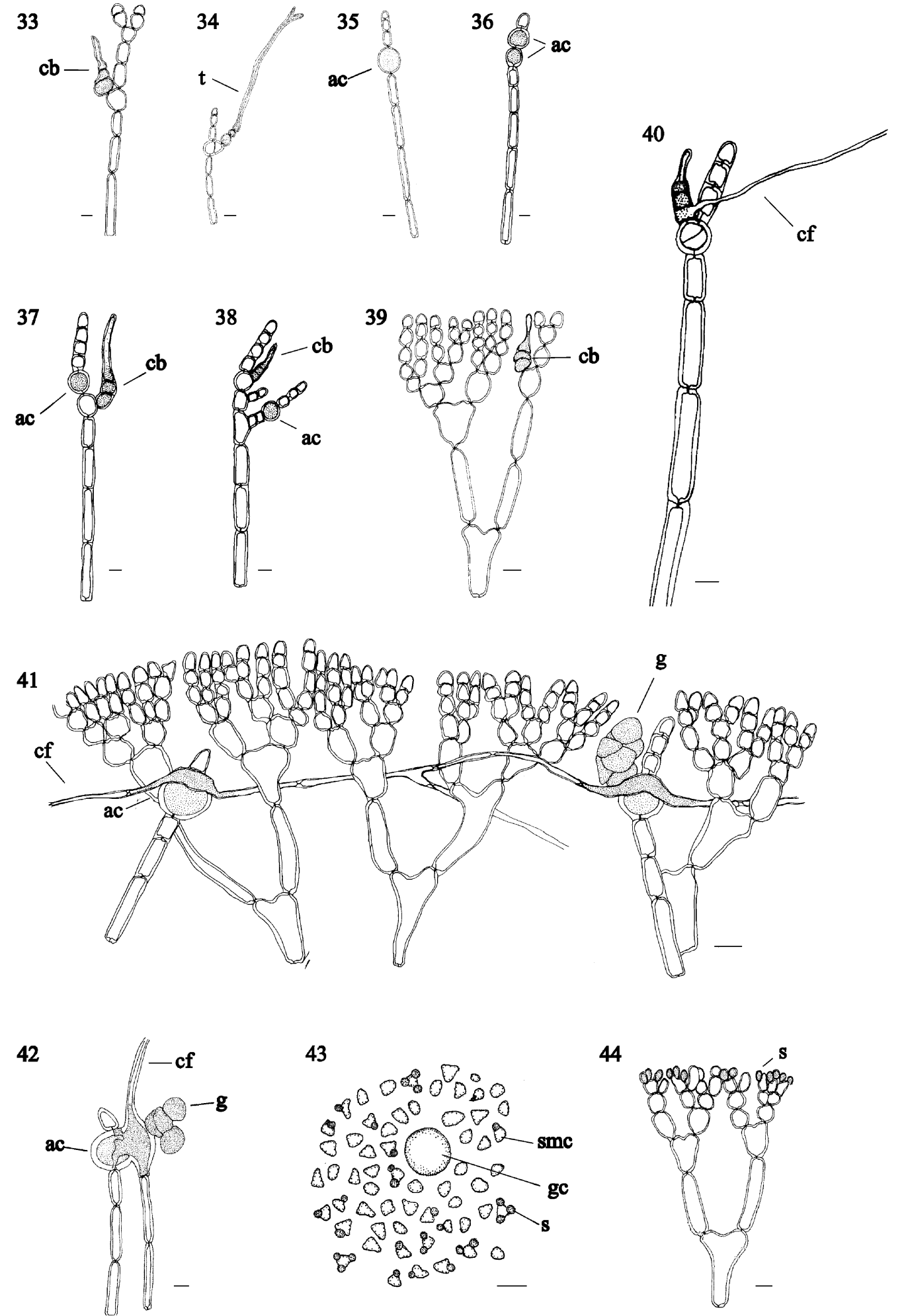

Figures 33-44 Reproductive structures of Nemastoma dumontioides J. Agardh.

(33) Three-celled carpogonial branch (cb) with short trichogyne on a rhizoidal filament (CAT 870). (34) Three-celled carpogonial branch supported by a divided supporting cell and with a long and bifurcated trichogyne (t) (CAT 870). (35) Intercalary auxiliary cell (ac) on a rhizoidal filament (CAT 870). (36) Two auxiliary cells (ac) situated consecutively on the same rhizoidal filament (CAT 870). (37-38) Three-celled carpogonial branch (cb) and an auxiliary cell (ac) situated on the same rhizoidal filament. The auxiliary cell is situated intercalarily in the rhizoidal filament itself in Figure 38, and intercalarily in a lateral branch off the rhizoidal filament in Figure 39 (CAT 870). (39) Three-celled carpogonial branch (cb) borne by a cortical fascicle (CAT 870). (40) Connecting filament (cf) issuing from the basal cell of the carpogonial branch (CAT 870). (41) Connecting filaments (cf) connecting two auxiliary cells (ac) and young gonimoblast (g) issuing from the connecting filament (CAT 870). (42) Early development of the gonimoblast (g) arising from connecting filament (cf) near the contact to the auxiliary cell (ac) (H 2354). (43-44) Spermatangial structures. Up to three spermatangia (s) are produced from terminal spermatangia mother cells (smc). Note the gland cell $(\mathrm{gc})(\mathrm{H} 2355)$. Scale bars for Figures $33-44=10 \mu \mathrm{m}$. 
Table 3 A comparison between the taxonomic characteristics of Nemastoma dichotomum and $N$. dumontioides.

\begin{tabular}{|c|c|c|c|}
\hline & & N. dichotomum & N. dumontioides \\
\hline \multicolumn{4}{|l|}{ HABIT } \\
\hline Height (cm) & & $7-8$ & 8 \\
\hline Thallus section & & $\begin{array}{l}\text { Cylindrical in basal part, compressed or } \\
\text { cylindrical in middle part, and usually } \\
\text { compressed in upper part }\end{array}$ & Cylindrical \\
\hline Texture & & $\begin{array}{l}\text { Cartilaginous except occasionally the upper part } \\
\text { in pressed individuals }\end{array}$ & $\begin{array}{l}\text { Gelatinous in fresh individuals and membranous } \\
\text { in pressed individuals }\end{array}$ \\
\hline Base & & Occasionally caespitose & Often caespitose \\
\hline Branching & & Irregularly pseudodichotomous & $\begin{array}{l}\text { Regularly pseudodichotomous with corymbose } \\
\text { outline }\end{array}$ \\
\hline Segments, diameter (mm) & & $1-5$ & $4-5$ \\
\hline Interdichotomy length & & Constant, except for the upper ones & Decreasing gradually from the base to the apices \\
\hline Terminal segments & & $\begin{array}{l}\text { Highly variable, digitate, var. dichotomum } \\
\text { ligulate, var. biasolettianum } \\
\text { wedge-shaped: var. caulescens } \\
\text { spathulate: var. incrassatum }\end{array}$ & Cylindrical, short, occasionally ligulate \\
\hline \multicolumn{4}{|l|}{ VEGETATIVE STRUCTURES } \\
\hline Outer cortical cells & $\begin{array}{l}\text { form } \\
\text { length }(\mu \mathrm{m}) \\
\text { diameter }(\mu \mathrm{m})\end{array}$ & $\begin{array}{l}\text { Ovoid, club-shaped, rounded or elongated } \\
\text { (4-) } 8(-15) \\
\text { (4-) 6-8 }\end{array}$ & $\begin{array}{l}\text { Ovoid, club-shaped, rounded or elongated } \\
\text { (2-) 6-8 } \\
4-6\end{array}$ \\
\hline Medullary cells & $\begin{array}{l}\text { length }(\mu \mathrm{m}) \\
\text { diameter }(\mu \mathrm{m})\end{array}$ & $\begin{array}{l}\text { Up to } 440 \text { (580, according to Athanasiadis } 1988) \\
5-12\end{array}$ & $\begin{array}{l}\text { Up to } 350 \\
6-10\end{array}$ \\
\hline Cells of the rhizoidal filaments, length $(\mu \mathrm{m})$ & & Up to 70 & Up to 70 \\
\hline Gland cells, length $x$ diameter $(\mu \mathrm{m})$ & & $10-28(-38) \times 8-22(-30)$ & $12-23 \times 12-18$ \\
\hline ‘Glandular' hairs & & Occasionally present & Observed in only one specimen \\
\hline \multicolumn{4}{|l|}{ REPRODUCTIVE STRUCTURES } \\
\hline Monoecious/dioecious & & Monoecious & Dioecious \\
\hline Type of reproduction & & Apomictic & Sexual or apomictic \\
\hline \multirow[t]{3}{*}{ Carpogonial branch } & number of cells & $(2-) 3(-4)$ & $(2-) 3$ \\
\hline & carpogonium, length $(\mu \mathrm{m})$ & $5-40(-220)$ & $5-240$ \\
\hline & position & Lateral on rhizoidal filaments & $\begin{array}{l}\text { Lateral or, occasionally terminal, on rhizoidal } \\
\text { filaments, very rarely lateral on cortical fascicles }\end{array}$ \\
\hline Auxiliary cells, diameter $(\mu \mathrm{m})$ & & $8-18$ & $14-17$ \\
\hline Connecting filaments & & Absent & Present in sexually reproducing individuals \\
\hline Carposporangia diameter $(\mu \mathrm{m})$ & & $10-24$ & $12-23$ \\
\hline Spermatangia & & Single or in groups of $2-3$ & Single or in groups of $2-3$ \\
\hline GEOGRAPHICAL DISTRIBUTION & & Adriatic Sea, Aegean and Ionian Seas & Western Mediterranean, Adriatic Sea (?) \\
\hline
\end{tabular}

We have yet to find any specimen that fits the description of Reinsch's $N$. inconspicuum or any tetrasporangial plant, so the attribution of this entity is highly dubious. According to Cortel-Breeman and van den Hoek (1970) and van den Hoek et al. (1972), the development of carpospores of $N$. dichotomum gives rise to a tiny and filamentous stage producing monospores. As these authors did not describe nor give the origin of the gametophytic plants they studied, the filamentous stage obtained cannot be assigned to either $N$. dichotomum or N. dumontioides.

Three species described by Kützing are relegated to variety status as a result of the present study: (i) $N$. dichotomum var. biasolettianum, (ii) $N$. dichotomum var. caulescens and (iii) $N$. dichotomum var. incrassatum (Table 4). The last two are restricted to the Adriatic Sea, whereas the former is present both in the Adriatic Sea and in the Aegean and Ionian Seas. No relation can be hypothesized between the form and habitat of any of the varieties because the habitat information is, in most cases, not available. In addition, some specimens presumably collected from the same place, and sometimes even on the same date, present very different morphologies. Athanasiadis (1988: 26) has emphasized the morphological differences existing between the lectotype and the syntypes of $N$. dichotomum, which all originate from Trieste, and our results show that all the syntypes belong to $N$. dichotomum, although some represent different varieties. Nemastoma constrictum and $N$. constrictum var. longitrichogynum are reduced to synonymy with $N$. dichotomum var. caulescens, as the characteristics listed by Ercegovic (1949) for distinguishing $N$. constrictum from $N$. dichotomum are not consistent: the frond constrictions are not evident in Ercegovic's specimen of $N$. constrictum that is deposited in the J. Feldmann Herbarium, and the '2-celled carpogonial branches lateral on cortical fascicles' that he described, are actually 'glandular-like' hairs. Likewise, N. constrictum var. longitrichogynum must also be rejected as a separate taxon because the structures identified and illustrated by Ercegovic as being 'carpogonial branches' up to $1000 \mu \mathrm{m}$ long also appear to be 'glandular-like' hairs.

Nemastoma dichotomum and $N$. dumontioides are probably very closely related taxa, with the former pos-

Table 4 Recommended taxonomic changes.

\begin{tabular}{lll}
\hline Proposed taxa & Basionym & Heterotypic synonyms \\
\hline $\begin{array}{l}\text { Nemastoma dichotomum var. } \\
\text { biasolettianum (Kützing) Rodríguez-Prieto, } \\
\text { Verlaque et Vergés comb. nov. et stat. nov. }\end{array}$ & $\begin{array}{l}\text { Gymnophlaea biasolettiana Kützing } \\
(1843)\end{array}$ & - \\
$\begin{array}{l}\text { Nemastoma dichotomum var. caulescens } \\
\text { (Kützing) Rodriguez-Prieto, Verlaque et }\end{array}$ & Gymnophlaea caulescens Kützing & Nemastoma constrictum Ercegovic (1949) \\
$\begin{array}{l}\text { Vergés comb. nov. et stat. nov. } \\
\text { Nemastoma dichotomum var. incrassatum }\end{array}$ & Gymnophlaea incrassata Kützing & N. constrictum var. longitrichogynum \\
(Kützing) Rodríguez-Prieto, Verlaque et & $(1843)$ & Ercegovic (1949) \\
Vergés comb. nov. et stat. nov. & &
\end{tabular}


sibly derived from the latter by the acquisition of apomixis. The likelihood that $N$. dichotomum reproduces apomictically was first suggested by Athanasiadis (1988) based on a comparison of the lectotype (LD 22089) with recently collected plants from the Aegean and Adriatic Seas, in all of which gonimoblast initials arose directly from auxiliary cells, without any contact by connecting filaments. The absence of connecting filaments in all the female gametophytes of $N$. dichotomum studied here supports this hypothesis. Apomictic reproduction, which favors the preservation of random mutations, would also explain the high polymorphism displayed by $N$. dichotomum, unlike $N$. dumontioides in which sexual reproduction and little morphological variation are the norm. Consequently, until a molecular-genetic study of Mediterranean Nemastoma populations is carried out, we maintain $N$. dumontioides as distinct from $N$. dichotomum

\section{Key to the Mediterranean species and varieties of Nemastoma J. Agardh}

1. Thallus gelatinous throughout, drying membranous; cylindrical, regularly pseudodichotomous with corymbose outline; interdichotomies decreasing gradually in length from the base to the apices; sexual or apomictic ................................... dumontioides

1. Thallus cartilaginous except distally; cylindrical basally, cylindrical or compressed medially, usually compressed distally; irregularly pseudodichotomous; interdichotomies not decreasing gradually in length from the base to the apices; apomictic N. dichotomum - 2

2. Interdichotomies increasing in length towards the upper parts; upper parts ligulate

N. dichotomum var biasolettianum

2. Interdichotomies decreasing in length towards the upper parts; upper parts not ligulate .................. 3

3. Upper parts wedge-shaped; axis up to $5 \mathrm{~mm}$ wide N. dichotomum var. caulescens

3. Upper parts spathulate; axis up to $1.5-2 \mathrm{~mm}$ wide N. dichotomum var. incrassatum.

\section{Acknowledgements}

This project (PB95-0385-C06-06) was supported by a grant of the Ministerio de Educación y Cultura (Spain). We would like to thank Drs A. Athanasiadis and G. Kraft for their valuable comments and assistance with the literature and $\mathrm{Dr} \mathrm{E}$. Ballesteros for providing some of the specimens used in this study. We are also grateful to Drs S. Riebe and P. Lassen for the loan of Agardh's specimens from the Herbarium of the Botanical Museum of Lund, Dr W.F. Prud'homme van Reine for the loan of Kützing's specimens from the Rijksherbarium, Leiden, $\operatorname{Dr} \mathrm{B}$. de Reviers for the loan of the original material of Ercegovic preserved in the Herbaria of J. Feldmann (Muséum National d'Histoire Naturelle, Paris), Drs M. Cormaci and G. Bressan for providing facilities for examining specimens from the Herbaria of the Universities of Catania and Trieste, respectively, Prof. Maria Cristina Buia for the photograph of the specimen collected by G. Berthold in Naples, and Mrs M. Boudouresque for assistance with the literature.

\section{References}

Agardh, J.G. 1842. Algae maris Mediterranei et Adriatici, observationes in diagnosin specierum et dispositionem generum. Parisiis [Paris]. pp. x, 164.

Agardh, J.G. 1851. Species genera et ordines algarum, seu descriptiones succinctae specierum, generum et ordinum, quibus constituitur. Vol. 2: Florideae. Part 1, Lundae [Lund]. pp. xii, 351 (addenda and index).

Agardh, J.G. 1876. Species genera et ordines algarum [...]. Vol. 3, part 1. Lipsiae [Leipzig]. pp. vii, 724.

Agardh, J.G. 1879. Florideernes morphologi. Kongl. Svenska Vetensk.-Akad. Handl. 15 (6) (Ser. 4): 1-199, pls i-xxxiii.

Ardré, F. 1980. Observations sur le cycle de développement du Schizymenia dubyi (Rhodophycée, Gigartinale) en culture, et remarques sur certains genres de Némastomacées. Cryptogamie, Algol. 1: 111-140.

Athanasiadis, A. 1987. A survey of the seaweeds of the Aegean Sea with taxonomic studies on species of the tribe Antithamnieae (Rhodophyta). University of Gothenburg, Kungälv. pp. 174.

Athanasiadis, A. 1988. North Aegean marine algae. II. Studies on the thallus structure and reproduction of Nemastoma dichotomum J. Agardh and Predaea ollivieri J. Feldmann (Rhodophyta, Gigartinales). Bot. Mar. 31: 23-32.

Athanasiadis, A. 1996. Taxonomisk litteratur och biogeografi av skandinaviska rödalger och brunalger. Algologia publisher, Göteborg. pp. 280

Athanasiadis, A. 2002. Taxonomy and systematics of Rhodophyta with reference to the Mediterranean taxa. Flora Medit. 12: 93-168 (published in 2003).

Berthold, G. 1884. Die Cryptonemiaceen des Golfes von Neapel und der angrenzenden Meeres-Abschnitte. W. Engelmann, Leipzig. pp. ix, 27.

Børgesen, F. 1929. Marine algae from the Canary Islands, especially from Tenerife and Gran Canaria. III. Rhodophyceae. Part II. Cryptonemiales, Gigartinales and Rhodymeniales. Det Kgl. Danske Vidensk. Selsk. Biol. Medd. 8: 1-97.

Cortel-Breeman, A.M. and C. van den Hoek. 1970. Life-history studies on Rhodophyceae I. Acrosymphyton purpuriferum (J. Ag.) Kyl. Acta Bot. Neerl. 19: 265-284.

De Toni, G. 1936. Noterelle di nomenclatura algologica. VII. Primo elenco di Floridee omonime. (Privately published), Brescia. pp. 8.

De Toni, G.B. 1905. Sylloge algarum omniun hucusque cognitarum. Vol. IV. Florideae. Sectio IV. (Privately published), Patavii [Padova]. pp. 1523-1973.

Dixon, P.S. and L.M. Irvine. 1977. Seaweeds of the British Isles. Vol. 1. Rhodophyta. Part 1. Introduction, Nemaliales, Gigartinales. British Museum (Natural History), London. pp. xi, 252.

Ercegovic, A. 1949. Sur quelques algues rouges, rares ou nouvelles, de l'Adriatique. Acta Adriat. 4: 3-81.

Ercegovic, A. 1963. Contribution à la connaissance de certains genres d'algues rouges en Adriatique. Acta Adriat. 10: 1-54.

Feldmann, J. 1942. Remarques sur les Némastomacées. Bull. Soc. Bot. Fr. 89: 104-113.

Furnari, G., M. Cormaci and D. Serio. 1999. Catalogue of the benthic marine macroalgae of the Italian coast of the Adriatic Sea. Bocconea 12: 1-214

Guiry, M.D. and E. Nic Dhonncha. 2003. Algaebase. World-wide web electronic publication. www.algaebase.org.

Kraft, G.T. 1984. The red algal genus Predaea (Nemastomataceae, Gigartinales) in Australia. Phycologia 23: 3-20

Kützing, F.T. 1843. Phycologia generalis (oder Anatomie, Physiologie und Systemkunde der Tange). Leipzig. pp. ii, 458 [459=Verbesserungen].

Kützing, F.T. 1845. Phycologia Germanica [...], Nordhausen. pp. $\mathrm{x}, 340$.

Kützing, F.T. 1849. Species Algarum. Lipsiae. pp. xi, 922.

Kützing, F.T. 1866. Tabulae phycologicae, oder Abbildungen der Tange. Vol. 16. Nordhausen. pp. iii, 35 
Kylin, H. 1932. Die Florideenordnung Gigartinales. Lunds Univ. årsskr., N.F. Avd. 2, 28: 3-88.

Kylin, H. 1956. Die Gattungen der Rhodophyceen. C.W.K. Gleerup, Lund. pp. xv, 673.

Levring, T. 1974. The marine algae of the Archipelago of Madeira. Bol. Mus. Munic. Funchal 28: 5-111.

Lyle, L. 1920. The marine algae of Guernsey. J. Bot. 58 (Suppl. II): 1-53.

Masuda, M. and M.D. Guiry. 1994. The reproductive morphology of Platoma cyclocolpum (Nemastomataceae, Gigartinales) from Gran Canaria, Canary Islands. Cryptogamie, Algol. 15: 191-212.

Masuda, M. and M.D. Guiry. 1995. Reproductive morphology of Itonoa marginifera (J. Agardh) gen. et comb. nov. (Nemastomataceae, Rhodophyta). Eur. J. Phycol. 30: 57-67.

Montagne, C. 1839-1841. Plantae cellulares. In: (P. Barker-Webb and S. Berthelot, eds) Histoire naturelle des lles Canaries. 3, part 2, sect. 4. Paris, pp. xv, 208, pls 9 [pp. 1-16 (1839), 17160 (1840), 161-208, i-xv (1841)].

Oltmanns, F. 1904. Morphologie und Biologie der Algen. Erster Band. Spezieller Teil. G. Fisher, Jena. pp. vi, 733.

Reinsch, P.F. 1875. Contributiones ad algologiam et fungologiam. T.O. Weigel, Lipsiae. pp. xii, 103, pls 131.
Saunders, G.W. and G.T. Kraft. 2002. Two new Australian species of Predaea (Nemastomataceae, Rhodophyta) with taxonomic recommendations for an emended Nemastomatales and expanded Halymeniales. J. Phycol. 38: 1245-1260.

Silva, P.C. 1980. Remarks on algal nomenclature VI. Taxon 29: 121-145.

Turner D., 1801. Ulva furcellata et multifida, descriptae. J. für die Bot. (Schrader) 1800, 1: 300-302, pl. i.

van den Hoek, C., A.M. Cortel-Breeman, H. Rietema and J.B.W. Wanders. 1972. L'interprétation des données obtenues, par des cultures unialgales, sur les cycles évolutifs des algues. Quelques exemples tirés des recherches conduites au laboratoire de Groningue. Mem. Soc. Bot. Fr.: 45-66.

Verlaque, M. 1990. Contribution à l'étude du genre Predaea (Rhodophyta) en Méditerranée. Phycologia 29: 489-500.

Womersley, H.B.S. 1994. The marine benthic flora of southern Australia. Part IIIA. Bangiophyceae and Florideophyceae (Acrochaetiales, Nemaliales, Gelidiales, Hildenbrandiales and Gigartinales sensu lato). Australian Biological Resources Study, Canberra. pp. 508.

Received 27 March, 2003; accepted 8 October, 2003 